
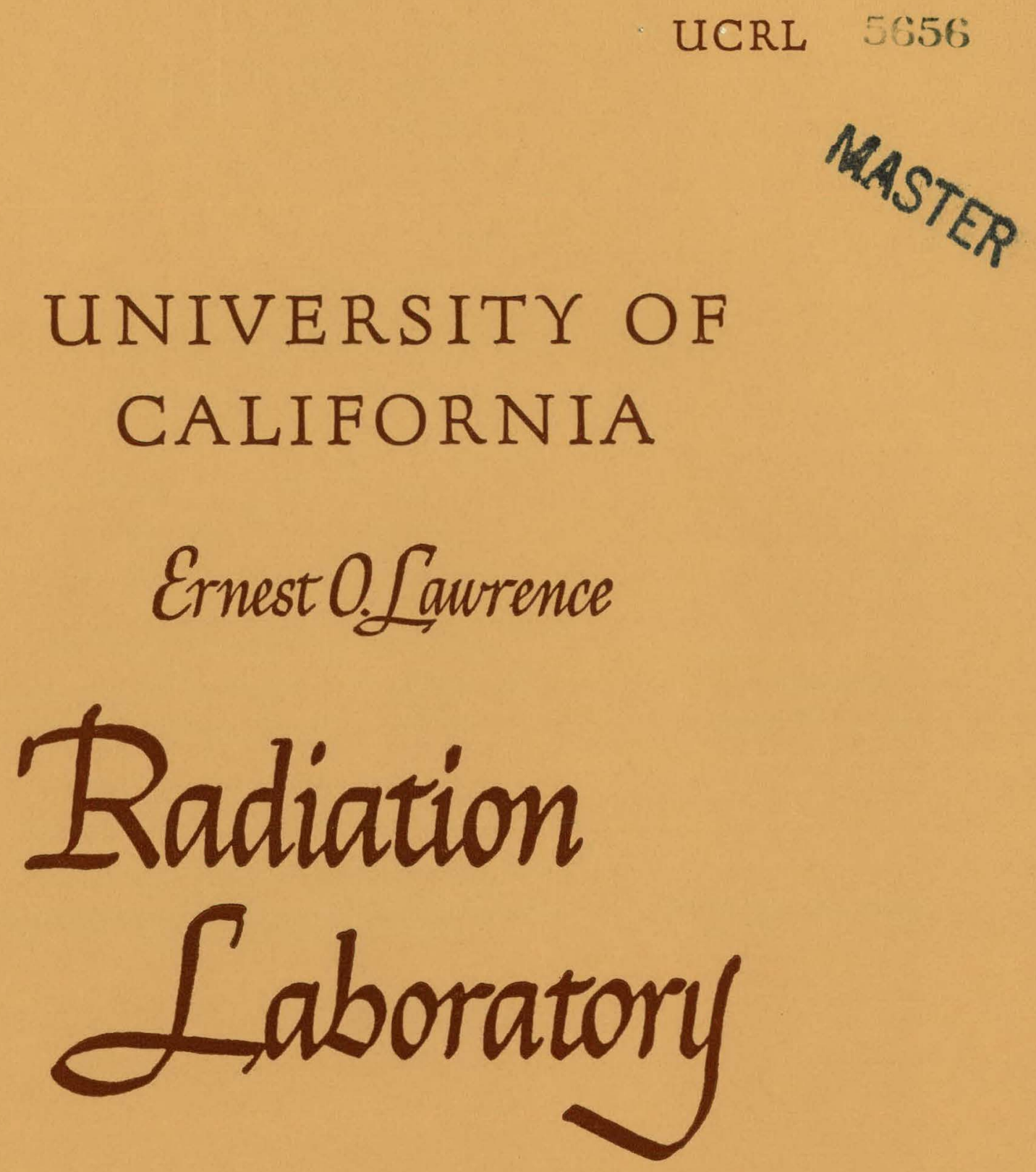

LIVERMORE SITE 


\section{DISCLAIMER}

This report was prepared as an account of work sponsored by an agency of the United States Government. Neither the United States Government nor any agency Thereof, nor any of their employees, makes any warranty, express or implied, or assumes any legal liability or responsibility for the accuracy, completeness, or usefulness of any information, apparatus, product, or process disclosed, or represents that its use would not infringe privately owned rights. Reference herein to any specific commercial product, process, or service by trade name, trademark, manufacturer, or otherwise does not necessarily constitute or imply its endorsement, recommendation, or favoring by the United States Government or any agency thereof. The views and opinions of authors expressed herein do not necessarily state or reflect those of the United States Government or any agency thereof. 


\section{DISCLAIMER}

Portions of this document may be illegible in electronic image products. Images are produced from the best available original document. 


\section{UNIVERSITY OF CALIFORNIA \\ Lawrence Radiation Laboratory \\ Livermore, California \\ Contract No. W-7405-eng-48}

TRANSISTOR DRIVEN BEAM SWITCHING TUBE DECADE COUNTER

Richard H. Graham

August 11, 1959

Printed for the U..S. Atomic Energy Commission 


\section{TRANSISTOR DRIV̈EN BEAM SWITCHING TUBE} DECADE COUNTER*

Richard H. Graham**

Lawrence Radiation Laboratory, University of California

Livermore, California

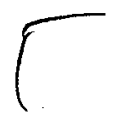

\section{ABSTRACT}

This paper describes an electrical readout, decade counter employing the magnetron beam switching tube with transistor drive. Double pulse resolution is one microsecond. The unit will accept a variety of transistor types and will tolerate supply voltage variations of $\pm 20 \%$ at ambient temper atures up to $60^{\circ} \mathrm{C}$.

A "Pixie" neon indicator is driven without the use of additional transistors. A readout circuit for printer on punched paper tape is presented.

' Work was performed under the Auspices of the U.S. Atomic:Energy Commission.

* Lawrence Radiation Laboratory, University of California, Livermore, California

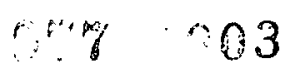




\title{
TRANSISTOR DRIVEN BEAM SWITCHING TUBE DECADE COUNTER*
}

\section{Richard H. Graham**}

\begin{abstract}
SUMMARY This paper describes an electrical readout, decade counter employing the magnetron beam switching tube with transistor drive. Double pulse resolution is one microsecond. The unit will accept a variety of transistor types, and will tolerate supply voltage variations of $\pm 20 \%$ at ambient temperatures up to $60^{\circ} \mathrm{C}$. A "Pixie" neon indicator is driven without the use of additional transistors. A readout circuit for printer on punched paper tape is presented.
\end{abstract}

\section{INTRODUCTION}

The design of a fast, reliable decade counter capable of neon front panel readout, together with provision for decimal printout, is a solved problem if electron tubes are employed. A transistor version of this device proves less straightforward than we might hope since neon lamp indicators either require separate transistor drivers or the use of high voltage transistors of presently somewhat limited characteristics, throughout the decade.

An alternative method of some merit for suitable applications is the use of the trochotron, or beam switching decade counter tube. The panel indicator problem is simplified since a "Pixie" single envelope neon decade indicator may be lighted directly by the available low voltage beam tubes. Decode complexities do not arise since the beam tube is in effect a decade stepping switch capable of sequentially supplying a few tenths of a milliampere to an external load at each of ten positions. The penalty for these advantages is a somewhat bulky package of an unhandy shape containing a permanent magnet and requiring filament power. The application must. settle the pros and cons of which type of counter is suitable.

The present counter, of the beam switching tube type, was designed for laboratory use in an automatic nuclear particle counting system requiring one microsecond double pulse resolution and counting rates of 10,000 counts per second. Three of these counters are connected in

* Work was performed under the auspices of the U.S. Atomic: Energy Commission.

* Lawrence Radiation Laboratory, University of California, Livermore, California 
cascade to form a scale of 1000, followed by an electromechañical readout register to provide six digits of decimal printout.

\section{BEAM SWITCHING TUBE}

Since the beam switching tube is the heart of this device, a brief description is in order. The electrons from a cathode located in perpendicular electric and magnetic fields form a beam which follows an equipotential; however, the individual electron paths are trochoidal, hence the name trochotron. When an electrode connected to the supply voltage through a resistor intercepts the beam, a self-locking action takes place such that any tendency of the beam to move from one side of this electrode is counteracted by changes in the electrode potential due to variations in the current through its load resistor. Only $15 \%$ of the beam current is required by this "spade" electrode for beam locking, the remainder is available as useful output through the "target" electrode adjacent. "Even" and "Odd" switch grids allow stepping of the beam from one target to the next when a negative potential is applied to the appropriate grid. Alternate negative pulsing of each set of grids will result in sequential stepping of the beam around the array of ten targets and spades. Interrupting the spade supply voltage causes the beam to "clear" or rotate without cathode current. Momentary reduction of one spade's potential will lock the beam in that position. In this manner the tube is reset to zero. A complete description of the trochotron may be found in the literature.

\section{DECADE COUNTER}

Bistable Multivibrator

Figure 2 is the schematic of the transistor bistable multivibrator or scale-of-two required to drive the beam tube grids alternately negative

\footnotetext{
${ }^{1}$ Kuchinsky, S., "Multi-output Beam Switching Tubes for Computers and General Purpose Use," IRE Convention Record, Pt. 6, Electron Devices, pages $43-45,1953$;

Romanus, H.; and Alfién, H. "Trochotrons - A New Family of Switching Tubes, "Tele-Tech, Vol. 13, page 94, June, 1954;

Bjórkman, J., and Lindberg, L., "Development of Trochotrons, "Trans. Roy. Inst. Technol, Stockholm, No. 80, 1954.
} 
with each successive input trigger pulse. The circuit consists essentially of two parts: $Q_{1}$ and $Q_{2}$ form a conventional ${ }^{2}$ medium-speed scale-of-two with diode pulse steering, $Q_{3}$ and $Q_{4}$ are the beam tube grid driver-amplifiers. Detailed operation is as follows:

When transistor $Q_{1}$ is conducting, its collector is close to ground potential and diode CR-1 is close to conduction. Diode CR-2 is reversebiased approximately 10 volts by the collector voltage of $Q_{2}$. A positive trigger will thus be "steered" to the base of $Q_{1}$ through $C R-1$, cutting off the transistor and forcing the circuit to change state such that $Q_{2}$ is conducting and $Q_{1}$ is off. The time constants of the multivibrator and pulse steering circuits are kept short, and $1 \mathrm{~N} 116$ restorer diodes are connected across the $3-k$ bias resistors to permit resolution of paired pulses less than one microsecond apart. The bases of both $Q_{1}$ and $Q_{2}$ are returned to $+1-1 / 2$ volts through $1-k$ resistors to reverse-bias the nonconducting base and render the circuit insensitive to ambient temperatures up to $60^{\circ} \mathrm{C}$. A saturation-type circuit is used to permit a larger beta spread in the transistors and to keep collector dissipation at a minimum. This last will profoundly affect transistor life. ${ }^{3}$

The emitter-base diode potential of the conducting transistor, $Q_{1}$, or $Q_{2}$, provides a base voltage source for the corresponding driveramplifiers $Q_{3}$ and $Q_{4}$. The 200-ohm resistors and 100-microhenry chokes are inserted in series with the base of $Q_{3}$ and $Q_{4}$ to provide isolation of the driver base during the trigger interval and the subsequent 'switching transient. The inductances, also furnish delayed overdrive to $Q_{3}$ or $Q_{4}$ after the multivibrator has switched. The 1 T 116 diode in series with the 3. 9-k resistor damps the overshoot of the choke.

This circuit has the advantage of permitting large (over 20 volt) collector swings into clamp diodes without loading of the multivibrator. The author has switched as high as 120 volts with selected 2 N247's in the driver stages. Trigger-in and driver collector waveforms are shown in Figure 3 .

"See, for example, Millman.J. and Taub, H., "Pulse and Digital Circuits" page 595, McGraw-Hill, 1956.

${ }^{3}$ Swanson, C., Application Report \#310, Landsdale Tube Co., Landsdale, $\mathrm{Pa}$.; "What's New," Electronic Industries, Vol. 18, No. 7, page 79 , July 1959. 
The multivibrator has a theoretical minimum d.c. transistor gain of 6, however, a lower limit of 15 is used for the scale-of-two, while 50 is the minimum used for the driver stages. The circuit is well adapted to the beta spread encountered in practice, since the low beta scale-of-two transistors show a slightly higher emitter base diode drop for a given collector current, insuring adequate base voltage on the higher gain drivers. The transistors are matched in pairs within $20 \%$ to achieve greater circuit reliability.

A variety of transistor types will operate satisfactorily in this circuit; among those tested are $2 N 247,2 N 370,2 N 417,2 N 484,2 N 316$, and 2N317. The more economical types are used in practice. Supply voltage fluctuations of $\pm 20 \%$ are tolerable at ambient temperatures up to $60^{\circ} \mathrm{C}$.

The combination of beam tube and multivibrator is shown schematically in Figure 4. The negative leading edge of the input signal switches transistor Q-8 momentarily into saturation. The upper trace of Figure 3 is the collector waveform of this transistor, supplying the positive trigger required by the scale-of-two. The driver outputs are connected to the "Even" and "Odd" beam tube switch grids.

$\underline{\text { Reset }}$

The beam tube is cleared and reset by externally interrupting the +24 -volts spade supply. The positive trailing edge of this waveform switches $Q_{1}$ into transient conduction for approximately 5 microseconds, bottoming its collector and the "zero" spade, thus resetting the beam tube to zero. $\Omega_{1}$ is normally biased off by the cathode voltage of $\mathrm{V}-1$. Indicator

$\mathrm{V}-2$ is the Pixie neon front panel indicator tube; each of its ten cathodes are connected to the corresponding beam tube target through an isolating resistor. The Pixie anode supply is +165 volts fed through a $56-k$ (external) resistor. The +35 target supply voltage appearing on an OFF target holds the Pixie below its 140-volt firing point. The 15-volt negative swing of an $O N$ target reduces the "bucking" target,voltage sufficiently to allow the neon tube to strike at the appropriate numeral. Subsequent firing of the next digit through the common load resistor extinguishes the previous digit, The anode voltage of each Pixie is externally adjustable to allow for aging and production spread in the tubes. While the numeral is not large 
or extremely bright, it is entirely adequate for the application since it merely serves as a pilot light for the electrical printout. Indicator anode current is approximately 150 microamperes.

Printout Circuit

The method of printout is shown in Figure 5. A ten-position stepping switch synchronized with the printer scans the beam tube decades. The low voltage at the selected digit will cause base current in the $2 \mathrm{~N} 247 \mathrm{switch}$; the collector current of this stage saturates the $2 \mathrm{~N} 144$, thus energizing the appropriate mercury relay which selects the digit to be printed or punched. +35 volts on an unselected position places reverse-bias on the 2 N247 base, holding it.de-energized.

Carry

As each decade arrives at a count of ten it is necessary to "carry" or transfer this pulse to the succeeding decade, through a high input-impedance circuit to prevent loading of the beam tube target. $Q_{3}$, 'the high input-impedance "bootstrap" emitter follower accomplishes this, since positive feedback to the base resistor through the 0.01 -microfarad coupling capacitor raises the effective value of this resistor by the factor $F=1 / 1-G$ where $G$ is the emitter follower gain. A value of 10 for $F$ is easily obtained; thus the shunting effect of the base bias bleeder is greatly reduced and negligible target loading results. The emitter follower $Q_{3}$ triggers blockingoscillator $Q_{2}$. The collector waveform of this stage is shown by the bottom trace in Figure 6. Positive output pulses are approximately 2 microseconds in duration with a negative 15-volt overshoot which is used to trigger the following decade.

Construction

The decades are plug-in units employing printed boards. Goldplated 2-ounce-copper etched wiring on a glass-epoxy substrate is used throughout. Transistors are socketed to facilitate matching where needed and to simplify maintenance (and save transistors!) when personnel unfamiliar with semiconductors must service the units.

\section{CONCLUSION}

All transistors are operated at $10 \%$ or less of their $25^{\circ} \mathrm{C}$ wattage ratings; since they are usually used as saturated or.cut-off switches, 
extremely low dissipation results. In service the counters are operated in an air-conditioned environment. Excellent life should result.from this combination of factors. While not enough data is presently available to justify the use of statistical formulae, it is gratifying to note that 6 of these counters have operated for over 2000 hours without failure. The manufacturer claims a 50,000-hour life potential for the beam switching tubes. We have yet to verify this in practice.

\section{ACKNOWLEDGMENT}

The author wishes to give credit for the basic concept of this device to R.C. Kaifer of the Lawrence Radiation Laboratory. 


\section{ILLUSTRATIONS}

Fig. 1-Decade counter.

Fig. 2 - Beam tube driver circuit diagram.

Fig. 3 - Trigger-in (top) and driver collector (bottom) waveforms. Sweep speed one microsec/cm; amplitude $10 \mathrm{v} / \mathrm{cm}$. (Time goes from right to left.)

Fig. 4-Decade counter circuit diagram.

Fig. 5 - Printout circuit diagram.

Fig. 6 - Decade counter input (top) and output waveforms. Sweep speed 40 microsec/cm; amplitude $10 \mathrm{v} / \mathrm{cm}$. (Time goes from right to left.) 


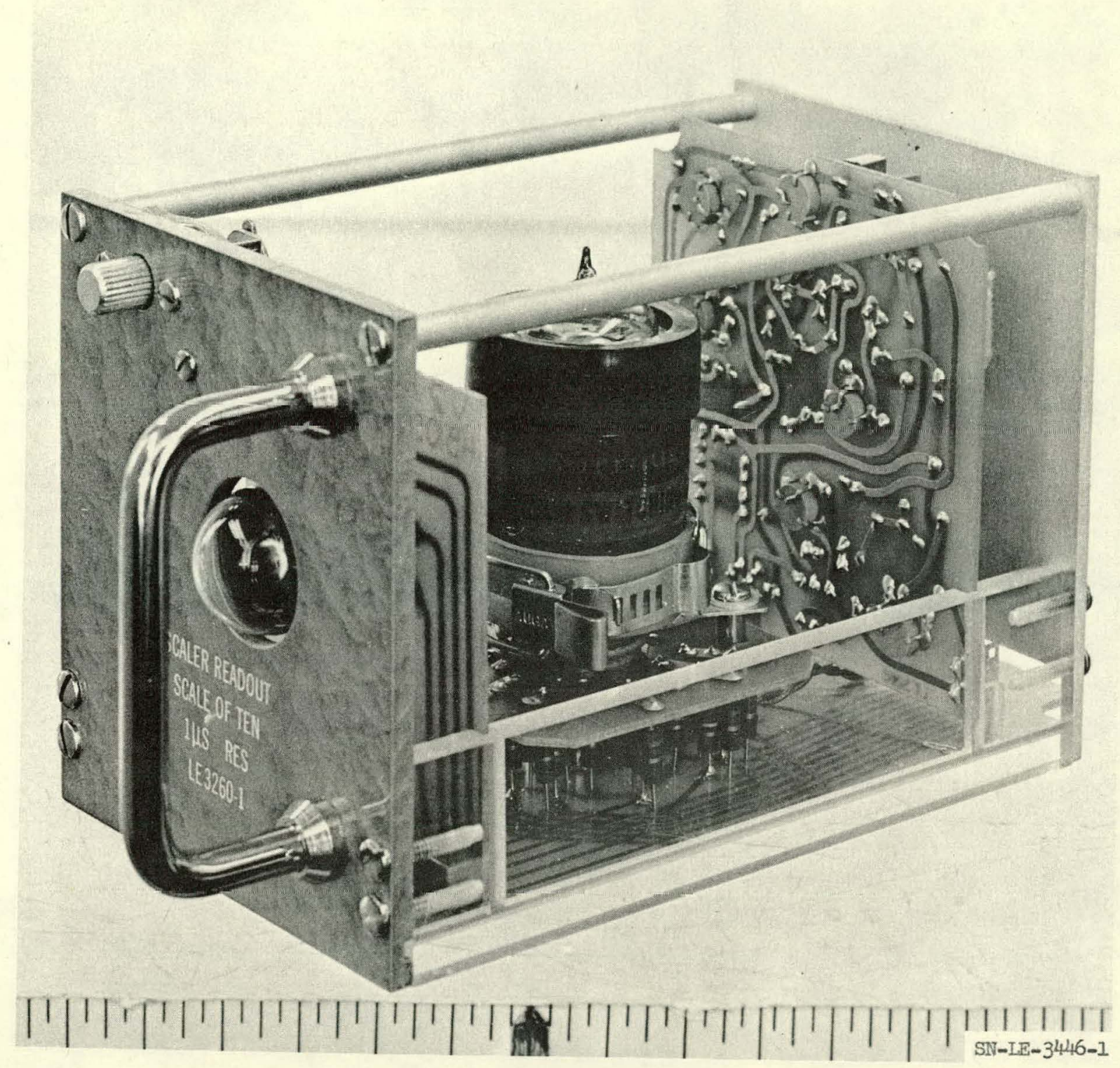

Fig. 1-Decade counter. 


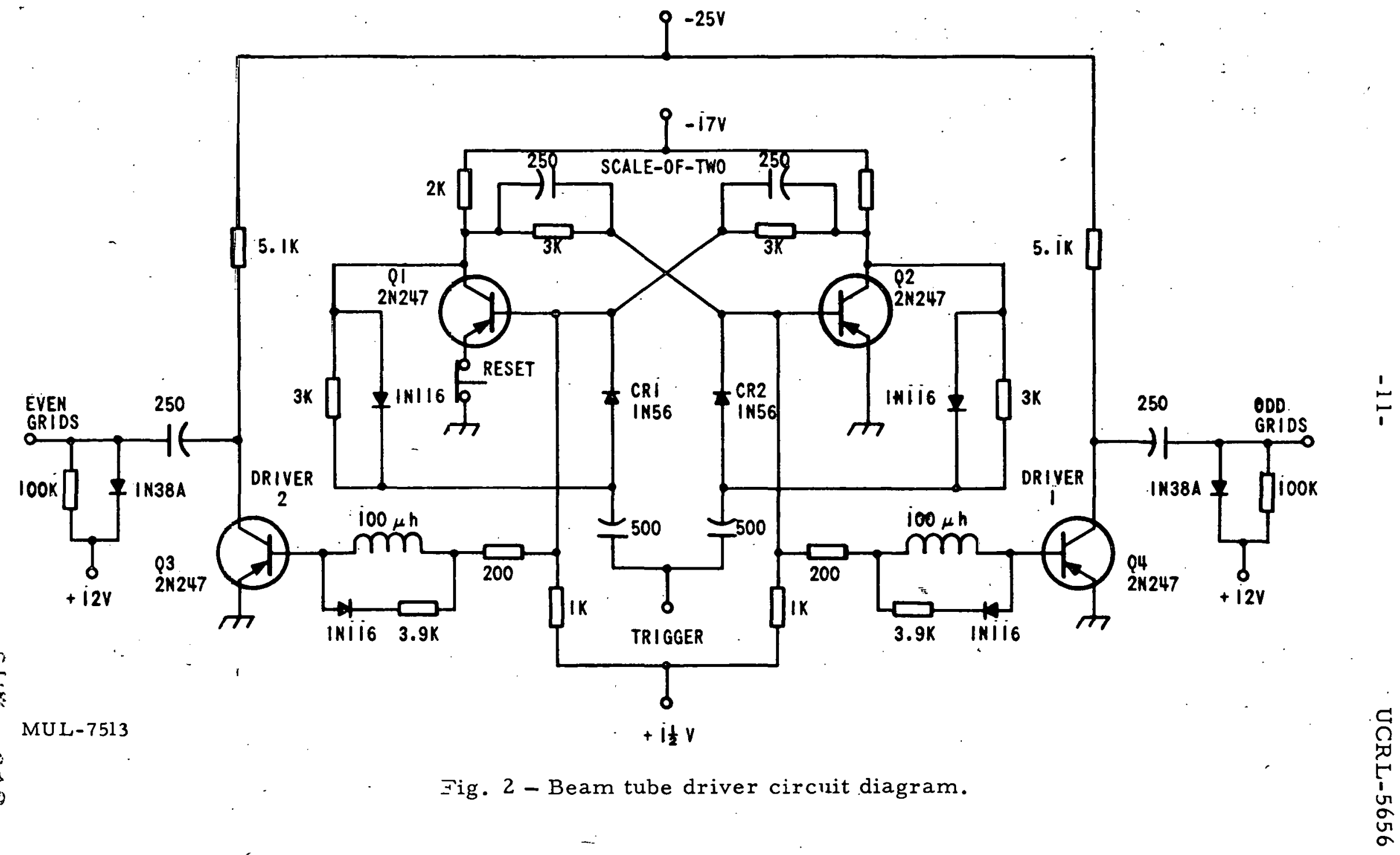



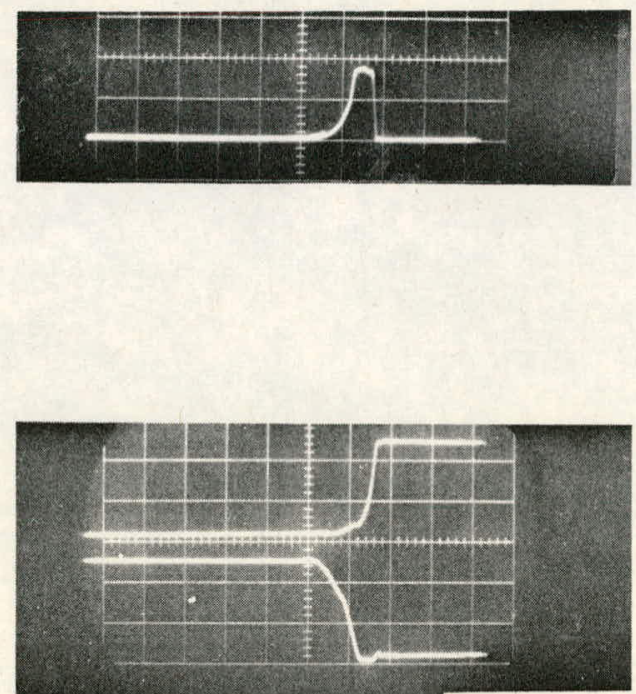

SN-17021

Fig. 3 - Trigger -in (top) and driver collector (bottom) waveforms. Sweep speed one microsec/cm; amplitude $10 \mathrm{v} / \mathrm{cm}$. (Time goes from right to left.) 


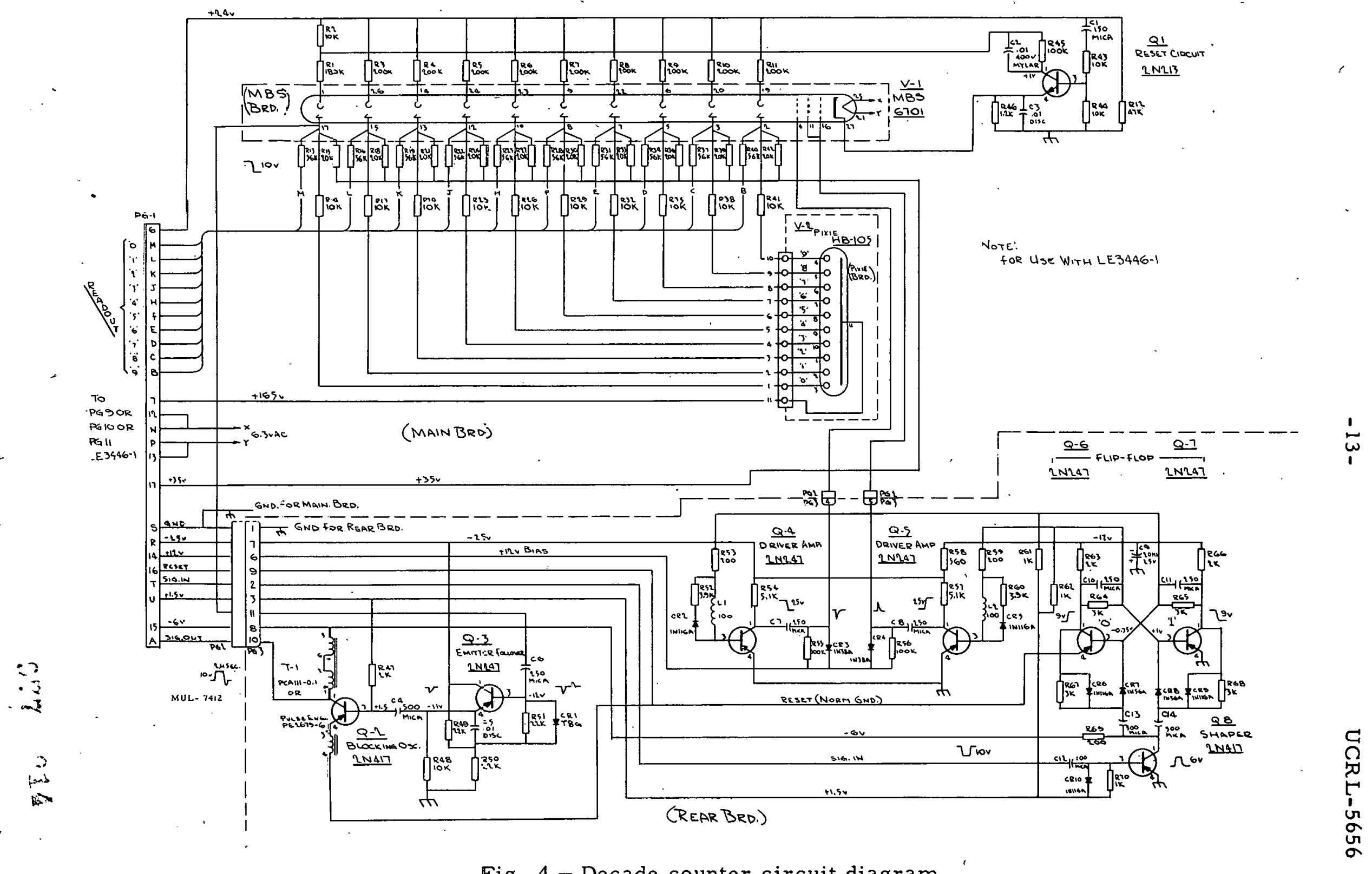

Fig. 4-Decade counter circuit diagram. 


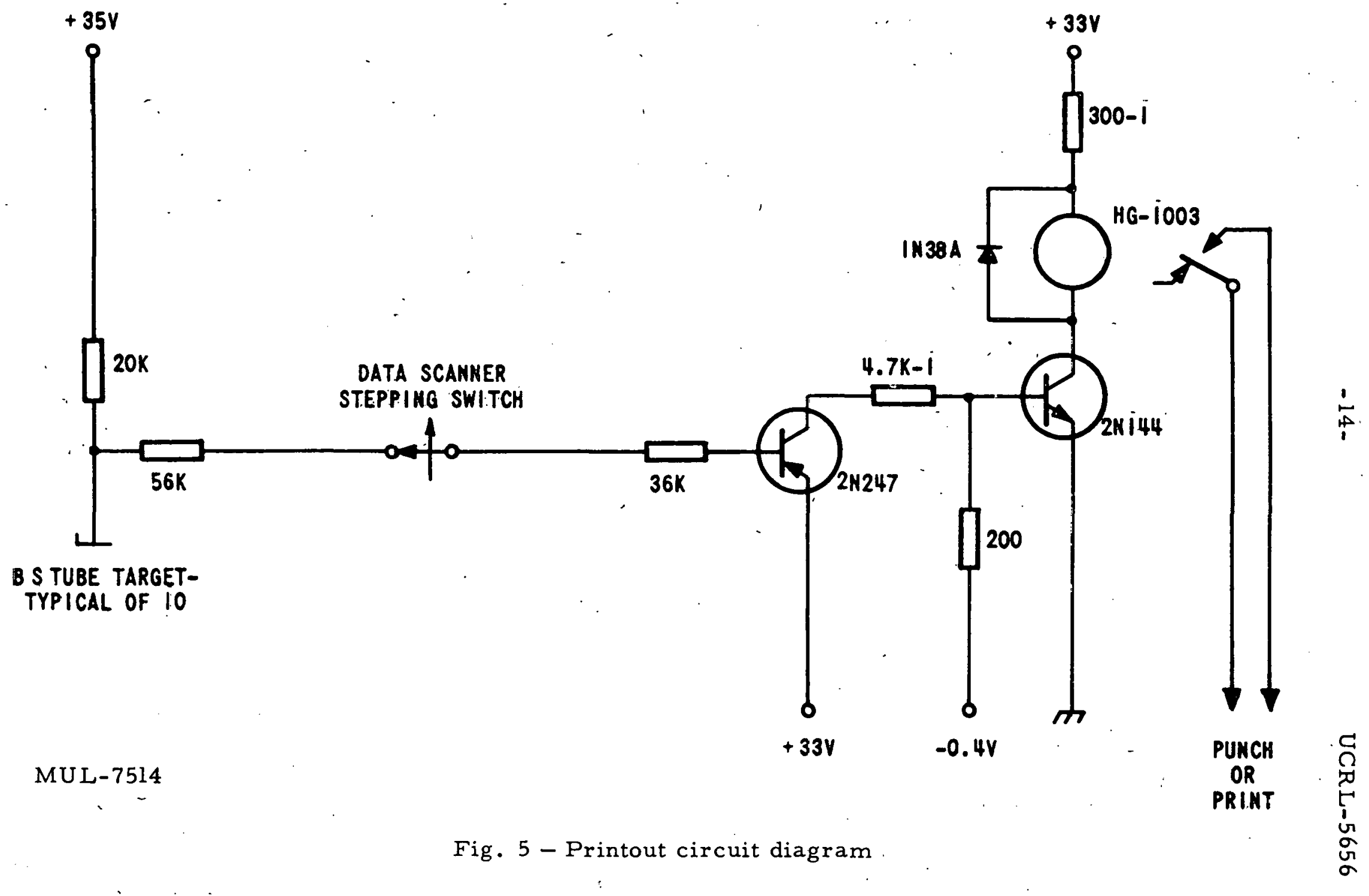




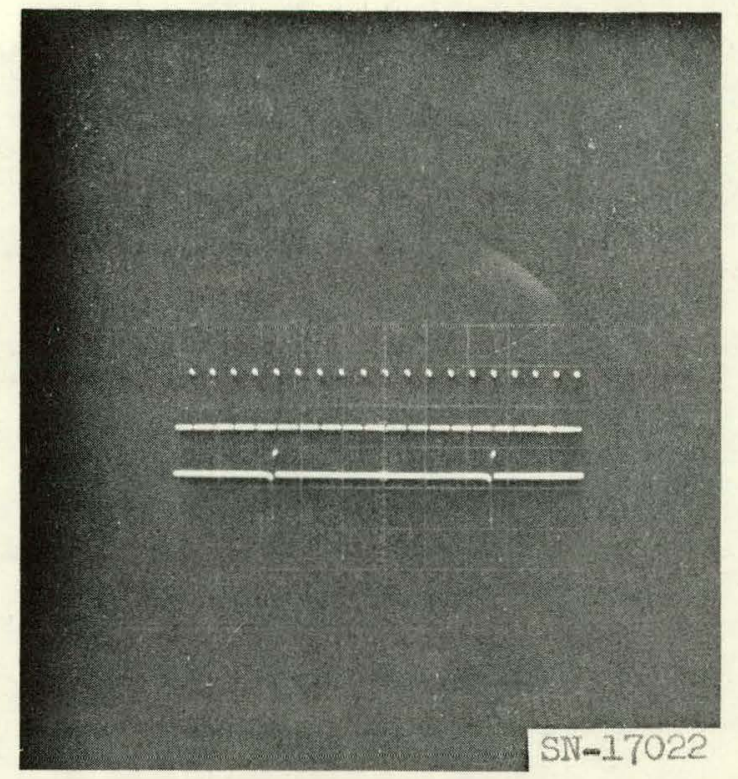

Fig. 6 - Decade counter input (top) and output waveforms. Sweep speed 40 microsec/cm; amplitude $10 \mathrm{v} / \mathrm{cm}$. (Time gocs from right to left.) 